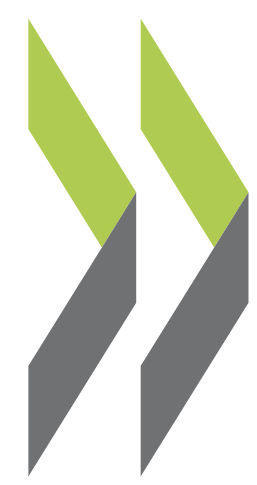

PEB Exchange, Programme on Educational Building 2008/10

\section{Sustainable Education} Campus in Spain: Nature and Architecture for Training

\section{Pablo Campos Calvo-} Sotelo

https://dx.doi.org/10.1787/241310445001 


\section{Sustainable Education Campus in Spain: Nature and Architecture for Training}

\section{By Pablo Campos, University Campus Planning and Design, Spain}

The sustainable education campus project for San Agustín de Guadalix is based on an innovative concept of urbanism and architecture. The campus design and landscape aim to support training and exemplify sustainability.

The Spanish energy company Iberdrola held an architectural competition for a campus dedicated to the corporate training of its employees at San Agustín de Guadalix on the site of a former learning centre on the outskirts of Madrid. The project presented here was among those submitted; its philosophy is based on two aims:

1. To create a sustainable education campus, where architecture and nature serve as cultural elements conveying values of environmental harmony and quality.

2. To generate an urbanistic/architectural space using renewable energy to promote sustainability and illustrate the identity of the company promoting the campus.

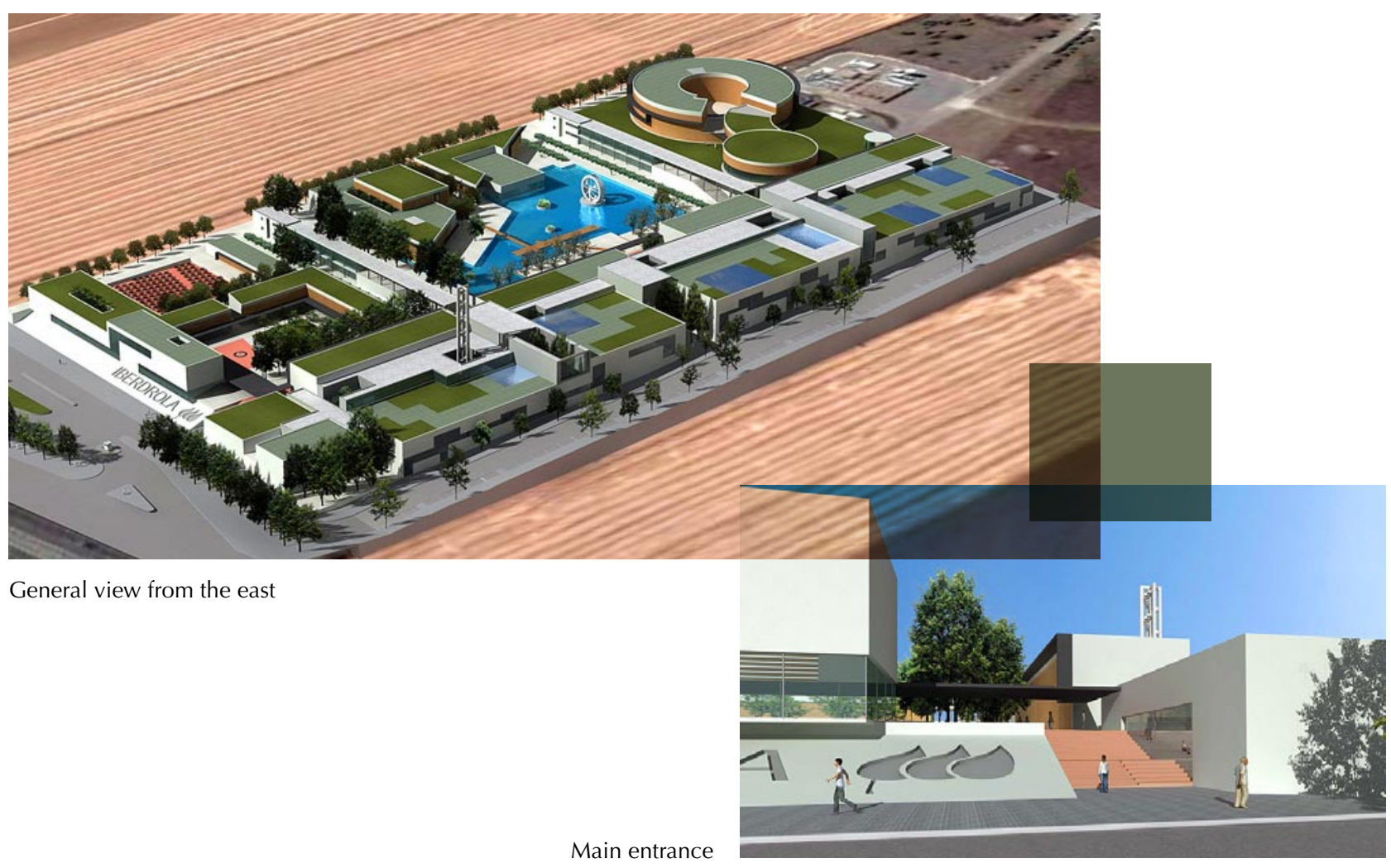


"The ... campus is a world in itself, a temporary paradise, a pleasant stage in life."

(Le Corbusier, 1936)

It is felt that a campus should incorporate values passed down through the centuries as centres of learning as well as expose the university's image to the world at large. The present project demonstrates the capacity both to educate and to portray itself as an example of sustainability and respect for nature.

\section{SUSTAINABLE EDUCATION CAMPUS}

"The curriculum embedded in any building instructs as fully and powerfully as any course taught in it." (David Orr, 2002)

\section{The concept}

The first lesson that a student receives is that provided by the campus, which should be a lesson in coherence, natural beauty and quality. To build a quality physical framework, nature and architecture must be more than a landscape setting and become teaching materials in themselves.

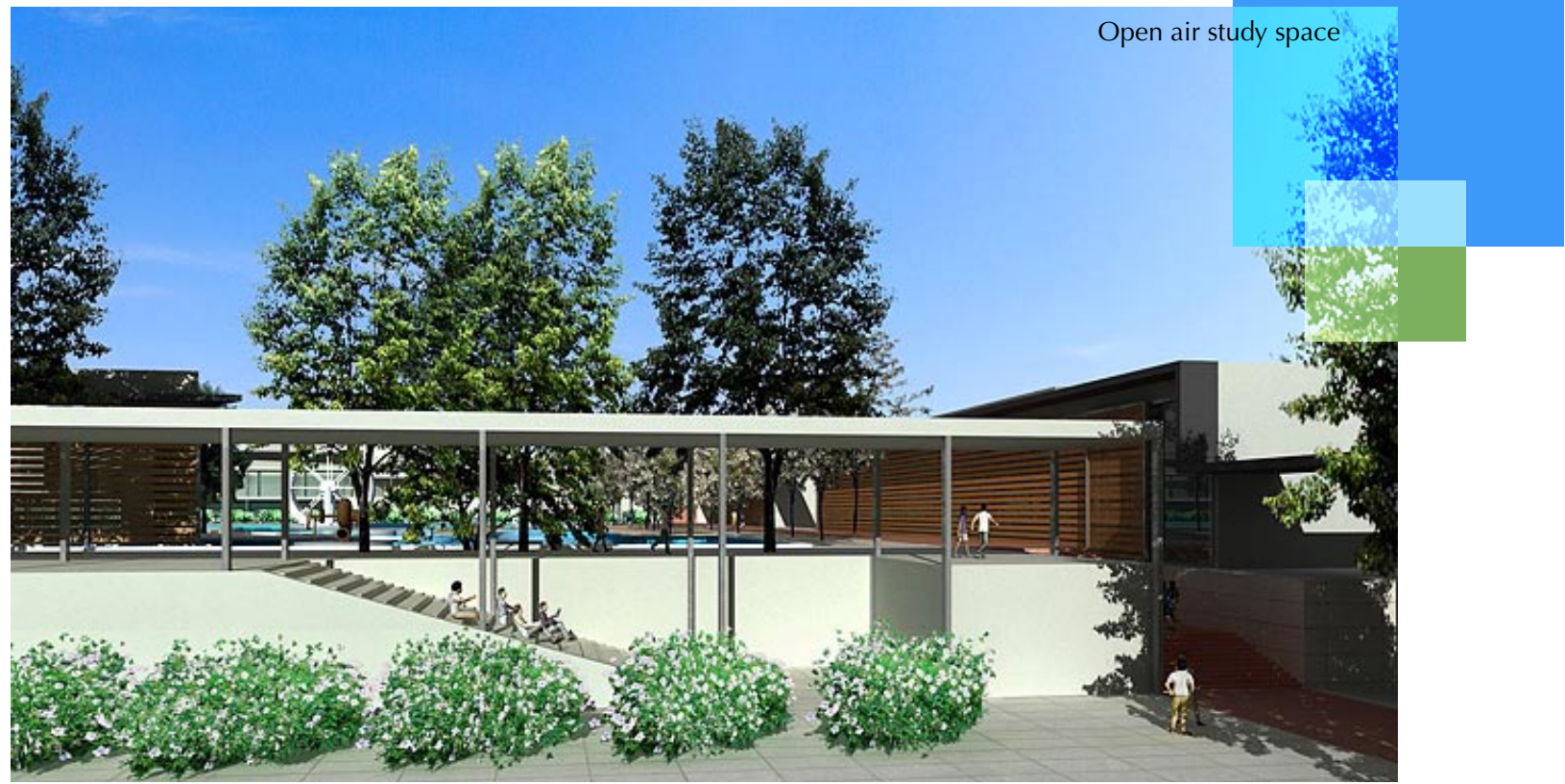

The sustainable education campus offers an environment which can stimulate educational activity, enhancing formal learning with the aesthetic component designed into the academic infrastructure. Human behaviour can be moulded by an environment that arouses an appetite for excellence and an understanding of the qualities latent in nature.

\section{In practice}

The Madrid campus project incorporates basic geometric shapes. There are two reasons for this: firstly, to encourage appreciation of the visual meaning in the different volumes; and, secondly, to associate each shape with types and uses of renewable energy. A section dedicated to the sun will be characterised by rectangular shapes (a symbol of stability and passiveness), a section devoted to water will take the form 
of triangles (representing movement and instability) while a section for wind will incorporate circular shapes (evoking dynamism).

This project is conceived on a human scale, in both the educational and functional sense. Any place on campus is a potential site for meetings and educational events, thus this complex gives pedestrians priority over wheeled traffic.

Architecture can show people how to relate to nature, teaching ecological values and environmental sustainability. That is the reason this San Agustín de Guadalix project advocates architecture dedicated to educating mankind, combining artistic and intellectual leadership with a commitment to its social context.

\section{DESIGN, TREATMENT AND MATERIALS}

"As a kind of city in microcosm, it [the campus] has been shaped by the desire to create an ideal community, and has often been a vehicle for expressing the utopian social vision of the American imagination."

(Paul Venable Turner, 1984)

The campus is organised in three sections representing the sun, water and wind, as mentioned above. Each section is planned as an environment for the renewable energies of the Iberdrola company:

- the sun: solar energy;

- water: hydraulic energy;

- wind: electrical energy.

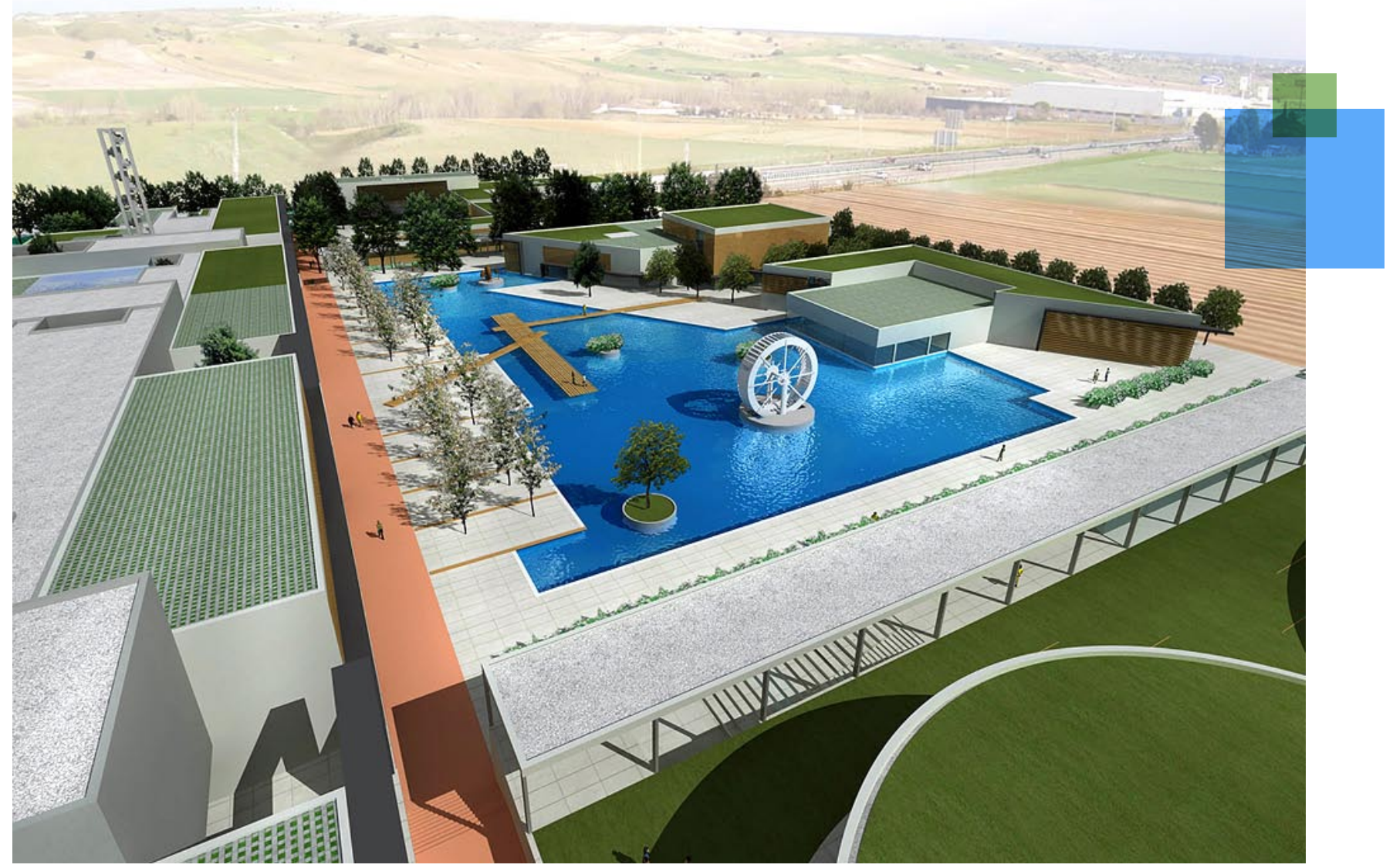




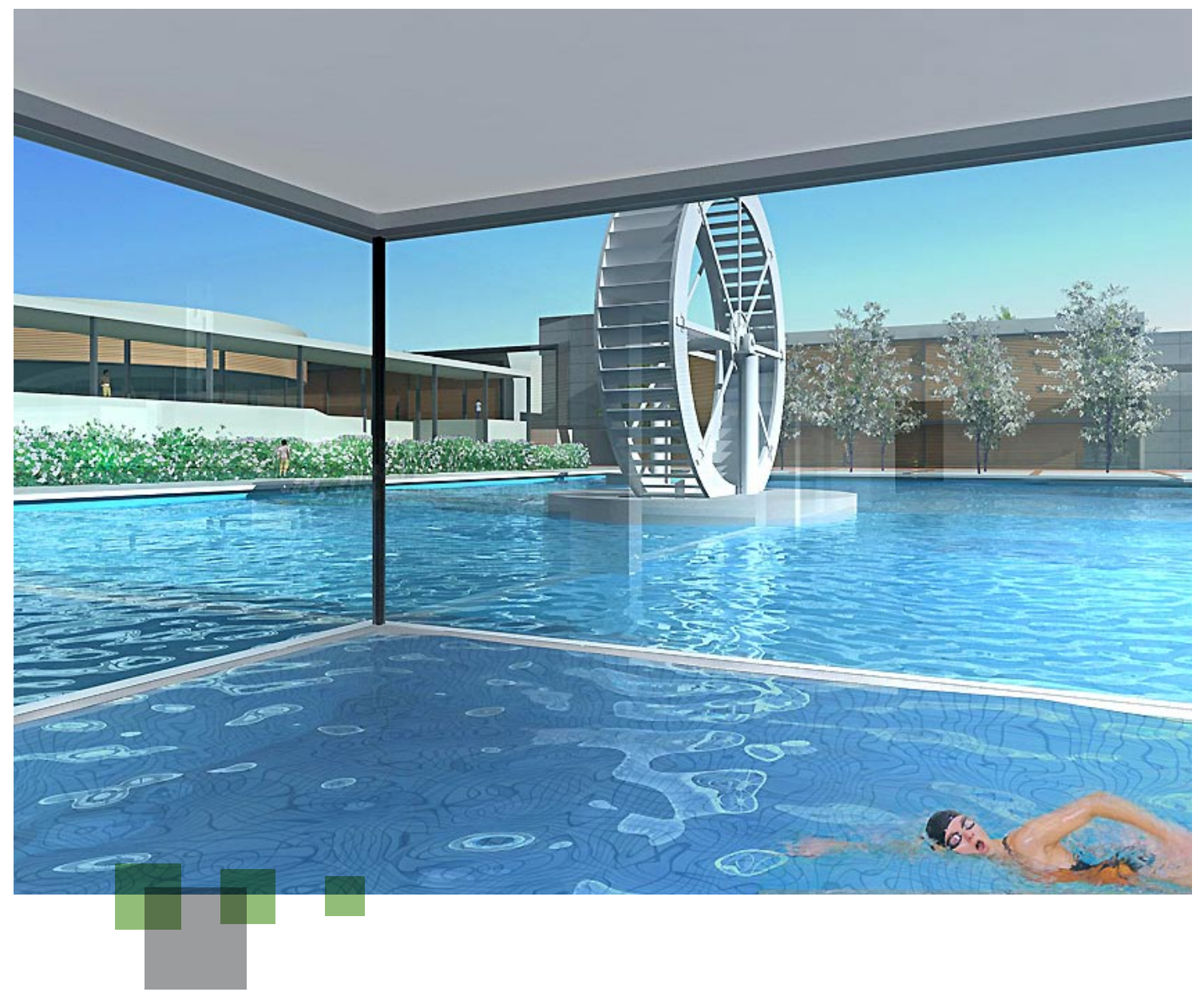

The design incorporates energy from renewable sources. Photovoltaic and thermal solar panels and a geothermal energy system provide electricity for the whole complex and offer a research framework for staff. Electricity, in combination with strategies such as solar shading, thermal mass to cool and natural ventilation, are used for the centralised production of the power necessary for the campus' air-conditioning and heating. Fan-coils installed in the interior spaces allow independent regulation of each area.

The characteristics of the area were studied to ensure that the urbanistic/architectural proposal would be properly rooted. They are as follows: upper Mesomediterranean bioclimatic belt, moderately dry, sandy-grained silica soils, average temperatures of $14.4^{\circ} \mathrm{C}$ and precipitation of around $469 \mathrm{~mm}$. The project proposes a specific treatment for the different campus sections, vegetation and new trees in line with these characteristics.

Native grasses would be planted in the general garden areas at minimal cost (EUR 200/hectare). Pools, in addition to offering visual relief, would contribute to the campus by freshening certain areas with a breeze and serving as a storage cistern to supply the complex and for use in fire fighting.

Ecological binding materials such as recycled powdered glass would cover paths and road surfaces.

The project pays special attention to the roofs of the buildings (the so-called "fifth façade of architecture"). For sustainability, ecologically green types of roofing and storage would be combined. 
As regards the architectural structure, a double skin system with wood on the outside and glass on the inside would be used, along with adjustable wood shutters sliding on metal frames. The shutters would be made of either natural coloured bamboo slats with an oil finish (a highly durable, minimummaintenance ecological material) or cedar wood autoclave treated with fungicide and insecticide (also low-maintenance).

The campus would require the partial replacement of some existing buildings. The work would involve recycling the metal girders, partially burying them and then using them as urban furniture and supports for wooden seats. In addition, the existing tower, visible from a great distance, would be recovered for the new campus as a monument to the heritage of the complex and new metal cladding added to its reinforced concrete structure.

\section{CONCLUSION}

The quality of education is intimately linked to its architecture. Any urbanistic/architectural project must stem from an in-depth study of the area's characteristics, taken in the broad geographical, climatic, cultural, functional and ideological sense. The site should provide the conceptual energy from which a campus draws life.

This requirement of professional rigour is especially critical in the design of "spaces for learning". The learning process cannot be separated from direct contact; modern forms of telecommunication must never seek to replace the close contact and direct exchange between people, the real stimulus for learning.

It is this belief which underlies the need to conceive urbanistic/architectural complexes whose chief objective is to promote the human dimension of integral training. This design of the sustainable education campus of Madrid deliberately chooses to avoid solutions which owe more to an excessively conclusive or iconic architecture, but rather advocates spaces which, through the energy provided by the beauty of nature, serve the mission of the campus: the all-round education of the human being.

For more information, contact the project designer:

Pablo Campos, PhD, Architect

University Campus Planning and Design

Urbanizacion Villagolf, 25

Villanueva de la Cañada

Madrid, Spain

E-mail: utoplan@telefonica.net

www.utoplan.com

The author wishes to acknowledge PROINTEC and MECSA with whom he collaborated. 


\section{ORGANISATION FOR ECONOMIC CO-OPERATION AND DEVELOPMENT}

The OECD is a unique forum where the governments of 30 democracies work together to address the economic, social and environmental challenges of globalisation. The OECD is also at the forefront of efforts to understand and to help governments respond to new developments and concerns, such as corporate governance, the information economy and the challenges of an ageing population. The Organisation provides a setting where governments can compare policy experiences, seek answers to common problems, identify good practice and work to co-ordinate domestic and international policies.

The OECD member countries are: Australia, Austria, Belgium, Canada, the Czech Republic, Denmark, Finland, France, Germany, Greece, Hungary, Iceland, Ireland, Italy, Japan, Korea, Luxembourg, Mexico, the Netherlands, New Zealand, Norway, Poland, Portugal, the Slovak Republic, Spain, Sweden, Switzerland, Turkey, the United Kingdom and the United States. The Commission of the European Communities takes part in the work of the OECD.

OECD Publishing disseminates widely the results of the Organisation's statistics gathering and research on economic, social and environmental issues, as well as the conventions, guidelines and standards agreed by its members.

This work is published on the responsibility of the Secretary-General of the OECD. The opinions expressed and arguments employed herein do not necessarily reflect the official views of the Organisation or of the governments of its member countries.

No reproduction, copy, transmission or translation of this publication may be made without written permission. Applications should be sent to OECD Publishing rights@oecd.org or by fax 331452499 30. Permission to photocopy a portion of this work should be addressed to the Centre français d'exploitation du droit de copie (CFC), 20, rue des Grands-Augustins, 75006 Paris, France, fax 331463467 19, contact@cfcopies.com or (for US only) to Copyright Clearance Center (CCC), 222 Rosewood Drive, Danvers, MA 01923, USA, fax 1978646 8600, info@copyright.com. 